\title{
COVID-19 y atención a embarazadas en el consultorio
}

\author{
COVID-19 and pregnancy care in the clinic
}

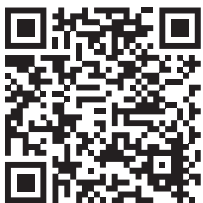

Jesús Carlos Briones-Garduño*

\section{RESUMEN}

La mujer embarazada aparentemente no parece ser más vulnerable que la población en general; sin embargo, se puede decir que no hay muchos datos o son escasos, y que los cambios fisiológicos y la respuesta inmune de los pacientes son similares a la mujer embarazada. Cuando se identifica a una paciente en este estado contagiada por COVID-19 en el consultorio general, debe consultarse a su ginecólogo o intensivista, dependiendo de sus condiciones. La paciente puede pasar por diferentes situaciones y se debe considerar que puede llegar a cuidados intensivos si las medidas preventivas no son suficientes. La valoración obstétrica debe ser siempre de forma individual y el control prenatal que se hace debe ser orientado con un enfoque de riesgo, identificar de manera temprana factores de riesgo y comorbilidades tanto de la madre como del feto.

Palabras clave: COVID-19, embarazo, obstetricia.

\section{ABSTRACT}

The pregnant woman does not seem to be more vulnerable than the general population, however, it can be said that there is not much data or it is scarce, and that the physiological changes and the immune response of patients are similar to that of pregnant women. When a pregnant patient infected with COVID-19 is identified in the general office, her gynecologist or intensivist should be consulted, depending on her conditions. The pregnant patient can go through different situations and it should be considered that she can reach intensive care if preventive measures are not enough. Obstetric assessment must always be individual and the prenatal control that is carried out must be oriented with a risk approach, early identification of risk factors and comorbidities of both the mother and the fetus.

Keywords: COVID-19, pregnancy, obstetrics.

* Director de Medicina Aguda y Auxiliares de Diagnóstico y Tratamiento: Hospital General de México Dr. Eduardo Liceaga.

Correspondencia: JCBG, drcarlosbriones@ yahoo.com.mx

Conflicto de intereses: No hay conflicto de intereses.

Citar como: BrionesGarduño JC. COVID-19 y atención a embarazadas en el consultorio. Rev CONAMED. 2020; 25(supl. 1): s15-s23. https://dx.doi. org/10.35366/97344 Financiamiento: No hubo financiamiento.

Recibido: 13/11/2020. Aceptado: 13/11/2020 


\section{INTRODUCCIÓN}

Las enfermedades emergentes son infecciosas y en las últimas décadas cobraron gran interés, en especial las de un grupo de virus denominados coronavirus, que a principios de este nuevo siglo generaron impacto con lo que se conoce como MERS y SARS, en las primeras publicaciones a principios de esta década fueron consideradas como la primera pandemia mundial.

Es importante mencionar que el movimiento de las poblaciones es muy importante para tratar de entender lo que sucede cuando una infección se disemina en forma masiva y da origen a una pandemia.

En el ámbito histórico, las bacterias y los virus nos han acompañado a lo largo de la historia de la humanidad, cada 100 años aproximadamente hemos tenido impacto con la peste negra, el cólera, la gripe española y ahora con estos coronavirus el MERS, SARS y COVID-19 que nos están impactando en todo el mundo.

EISARS es una enfermedad infecciosa emergente causada por coronavirus y la forma de detectarlas es a través de una reacción en cadena de polimerasa, con la cual se cuenta en todo el mundo incluyendo nuestro país. Estas infecciones respiratorias representan las principales causas de morbilidad y mortalidad en los seres humanos; sabemos que podemos tener infecciones por adenovirus, coronavirus, virus gripales o paragripales, sincitial respiratorio, rinovirus y algunos otros virus como estos coronavirus que nos están causando grandes problemas.

En el 2002, se difundió que el SARS estaba considerado como la primera pandemia global de este siglo. Mediante microscopia electrónica, se ha observado que estos virus se adhieren a las células, replican su genoma dentro de éstas y causan estragos en forma multisistémica.

La técnica de la cadena de polimerasa es la base para hacer el diagnóstico a nivel moleculary poder identificar que se trata de este coronavirus específico denominado COVID-19.

A continuación haremos una semblanza entre lo que es el síndrome respiratorio agudo severo (SARS), el síndrome respiratorio del Medio Este (MERS) y el COVID-19.

Para empezar, todos son betacoronavirus, todos se propician y se propagan en animales salvajes y de alguna manera han llegado con el ser humano, tienen periodos de incubación que se parecen mucho, al igual que la sintomatología clínica que oscila entre dos días y alrededor de una a dos semanas como máximo; algo que es importante que recordemos es el número básico de reproducción de este coronavirus, que oscila entre dos y tres, y esto habla de la capacidad infecciosa que tiene un virus para propagarse y la velocidad de transmisión, que es alta para el SARS-COV-2, y la mediana de la edad de los individuos afectados son, por lo general, de arriba de 50 años y que cuando se unen a alguna comorbilidad provocan mayores estragos.

\section{DEBE PROCURARSE AL DECIDIR LA HOSPITALIZACIÓN}

Cuando un paciente es valorado en el consultorio en el Servicio de Urgencias y se decide la hospitalización por las condiciones que presenta, sobre todo del aparato respiratorio, existen algunas recomendaciones globales generales, entre las que se encuentran: procurar que la habitación tenga presión negativa para no favorecer la diseminación de los virus; tratándose de mujeres embarazadas, el monitoreo materno y fetal es indispensable; tenemos que monitorear a través de ultrasonido y de pruebas de condición fetal cuáles son las condiciones de ese embrión/feto dependiendo de la edad gestacional y de la mamá; hay que monitorear todos los órganos y sistemas para poder hacer un diagnóstico integral.

En especial en obstetricia, se ha ideado un criterio que se conoce como "criterio q-SOFA» para establecer si en un momento presenta falla orgánica múltiple y cómo está repercutiendo en el feto para tomar acciones muy concretas y de carácter individual.

Una mujer puede desarrollar una neumonía viral y ésta va a tener repercusión en falla orgánica múltiple, se asocia y tiene repercusión en el desarrollo del feto. Son fetos que pueden nacer en forma prematura, pueden tener retraso en el crecimiento intrauterino e impacta en una mayor morbilidad y mortalidad materno-perinatal.

Las estadísticas de COVID-19 varían todos los días, podemos consultar a la Secretaría de Salud y saber cómo estamos variando, pero en el ámbito mundial se han reportado más de 19 millones de 
casos confirmados y de éstos tenemos una mortalidad que va de 716,000 a más defunciones, que dan una tasa de letalidad de 3.7\%.

En nuestro país, nos acercamos a casi medio millón de habitantes que están confirmados y tenemos el día de hoy más de 53 mil defunciones, estas estadísticas son muy cambiantes dada la dinámica de esta patología y del impacto poblacional. La mujer embarazada aparentemente no parece ser más vulnerable que la población general; sin embargo, podemos decir que no hay muchos datos, que son escasos y que los cambios fisiológicos y la respuesta inmune de los pacientes son similares a la mujer no embarazada.

No se ha demostrado transmisión vertical, aunque ya hay datos de infección en la placenta, hay vellositis causada por esto; sin embargo, aunque hay en la literatura el reporte de un recién nacido contagiado, no sabemos exactamente el mecanismo y puede ser similar a lo que sucede en la isoinmunización materno-fetal, por lo cual se recomiendan las medidas de aislamiento y vigilancia fetal para establecer un cuadro clínico y hemodinámico muy característico materno y fetal, y tomar las decisiones multidisciplinarias.

Cuando esta paciente es detectada en la consulta general, debe consultarse a un ginecólogo, a un materno-fetal o a un intensivista dependiendo de las condiciones.

Desde el punto de vista del laboratorio, está establecido por múltiples publicaciones que debemos solicitar una biometría hemática, porque aparte de que hacen leucocitosis, estos casos tienden a tener linfopenia y la relación de neutrófilo y linfocito es importante porque se pierde, cuantificar también moléculas de respuesta inflamatoria sistémica como la LDH, el dímero-D, la ferritina, la proteína c-reactiva, por supuesto la cuenta de linfocitos y la relación que hay y, si es posible, en los medios hospitalarios también cuantificar interleucinas y quimiocinas porque se ha hablado inclusive de una tormenta de citosinas en algunos casos, aunque esto no está del todo demostrado.

En cuanto a la respuesta inmunológica, es muy importante cuantificar la respuesta humoral a través de inmunoglobulinas como lgM, IgG y también la respuesta celular a través del CD3, CD4, CD8 y conocer la relación que hay entre CD4/CD8.
La radiografía de tórax y la tomografía axial computarizada son los auxiliares más importantes, de hecho la sensibilidad de la tomografía es tan alta que la dan como prototipo para hacer el diagnóstico, cuando en ésta nosotros tenemos imagen de vidrio despulido en el parénquima pulmonar prácticamente podemos asegurar que se trata de un paciente con COVID.

Las muestras virales para el diagnóstico a través de test de reacción en cadena de la polimerasa se obtienen de exudados o de aspirados faríngeos endotraqueal o inclusive de lavado alveolar para poder llevar al laboratorio a hacer una determinación molecular.

El Colegio Catalán de España nos da alguna guía para poder hacer un diagnóstico con bases de laboratorio, por supuesto que la PCR es la base para saber si este caso estuvo en contacto con el virus y ver la respuesta que tiene la IgM, que es la molécula que se produce rápidamente y luego la IgG que va a durar algunos meses como memoria.

El típico paciente negativo es el que tiene todas las fases en fase negativa y el típico positivo es aquel que da las tres moléculas positivas y esto nos sirve como orientación, en la literatura se habla mucho de la dexametasona y se utiliza en los hospitales en fase temprana con la idea de bloquear esta respuesta inflamatoria sistémica que puede volcar el organismo. Los linfocitos juegan un papel muy relevante en la respuesta inmunológica y esto se observa en los hospitales.

Algo muy importante es el tratamiento y todos sabemos que no existe uno específico; sin embargo, hay una diversidad de fármacos que están en fase de estudio y que se han ido reportando experiencias previas, que no tienen contraindicación durante el embarazo, por ejemplo, los inhibidores de proteasas con el uso de interferón, antipalúdicos como cloroquina o hidroxicloroquina que han estado en controversia en la literatura, inhibidores de la RNA-polimerasa, que es otro fármaco como el remdesivir que se utiliza mucho; sin embargo, no hay estudios concluyentes en la literatura y el tratamiento se basa en buscar optimizar o lograr las mejores condiciones entre la madre y el feto en un estrecho seguimiento clínico.

Vale la pena mencionar que en la literatura se habla un poco de la nitazoxanida, un fármaco antiviral que en principio se convirtió en 
un antiparasitario y ahora se convierte en una promesa antiviral.

También debemos mencionar a la vitamina D como un precursor o un modulador del sistema inmune, en los hospitales se ha descubierto que los casos más graves tienen niveles muy bajos de vitamina D en comparación con pacientes asintomáticos y obviamente el ácido fólico que está por supuesto indicado en toda mujer embarazada, pero que además, como nos dicen los genetistas y los bioquímicos, al favorecer procesos de metilación con la administración de este fármaco se mejora la calidad en general de las células y es altamente recomendable.

Lo que sucede entre un paciente con una evolución hacia la muerte y un paciente que sobrevive está relacionado con algunas interleucinas y quimiocinas, el propósito de los clínicos es bloquear de manera prematura esta explosión de quimiocinas y de interleucinas que no se ha demostrado en la mujer embarazada.

Los coronavirus entran a través de la vía respiratoria, colonizan tanto el aparato respiratorio como el aparato digestivo, pero podemos encontrar manifestaciones sistémicas inclusive en la piel de los sujetos, obviamente pasan por sistema nervioso, sistema cardiovascular, tubo digestivo incluyendo hígado, páncreas, riñón y pueden evolucionar hacia la falla orgánica múltiple.

\section{MANEJO DE LA INSUFICIENCIA RESPIRATORIA}

Es recomendable el inicio temprano del soporte respiratorio, oxígeno suplementario para mantener una saturación de éste arriba del 90\%, ya sea a través de mascarillas con reservorio que aseguren flujos de 10 a 15 litros por minuto, o bien optar por la ventilación mecánica invasiva, y aquí particularmente la ventilación protectora a través de un volumen corriente bajo que no vaya más de cuatro a seis mililitros por kilogramo, evitar una presión Plateau o una presión pico mayor a $30 \mathrm{~cm}$ de agua y mantener en los equipos de los ventiladores un PEEP menor a 15 centímetros de agua, ajustando con ellos sedación y relajación para optimizar el reclutamiento y la titulación del PEEP a base de compliancia, oxigenación y espacio muerto y por supuesto optimizando también la hemodinamia.
Habitualmente la presión, el índice de Kirby menor a 150 persistente en los pacientes, obliga a considerar el decúbito prono por lo menos de 16 horas y también un balance hídrico negativo para favorecer la oxigenación a nivel alveolocapilar, en caso refractario hay que considerar llevar a estos casos a membranas de oxigenación extracorpórea como es el ECMO o algunos otros dispositivos.

La paciente embarazada puede pasar por diferentes situaciones, y se debe considerar que puede llegar a cuidados intensivos después de que las medidas preventivas no fueron suficientes.

La atención particular obstétrica que nos debe interesar es el pinzamiento temprano del cordón umbilical y el aislamiento del neonato, hasta no tener certeza de las condiciones maternas y la pertinencia de la lactancia materna, todo esto en un clima de medidas preventivas tanto para nuestros pacientes como para el personal de salud que está inmerso en la atención de estos casos.

\section{EL MANEJO OBSTÉTRICO (MEDICINA MATERNO-FETAL)}

Requiere particular interés valorar algunos aspectos del manejo obstétrico, esto se propicia en las unidades de medicina materno-fetal, pero recordemos que en nuestro país la mayoría de las unidades obstétricas no tienen estos recursos y lo va a ver el médico general con esta atención dirigida o el ginecoobstetra.

La valoración obstétrica debe ser siempre en forma individual, el control prenatal que se hace en el consultorio debe ser orientado con un enfoque de riesgo, pensando en identificar en forma temprana factores de riesgo y comorbilidades tanto en la madre como en el feto, que puede en un momento dado propiciar un desenlace obstétrico desfavorable.

Siempre hay que tomar en cuenta la edad de la paciente y la vía de nacimiento, los casos severos se recomienda tratarlos en forma multidisciplinaria y siempre hay que descartar o aseverar, diagnosticar que puede encontrarse falla orgánica, sobre todo insuficiencia respiratoria que requiera el apoyo de oxígeno suplementario o el apoyo de la ventilación mecánica invasiva.

También es observable a nivel hospitalario que pueden ingresar por un cuadro respiratorio, un 
cuadro multisistémico de COVID, una infección viral, pero que éstas pueden ser presas de infección bacteriana y pueden tener un proceso mixto, también se debe sospechar de la sepsis materna, para hacer un diagnóstico puntual e iniciar tempranamente antibióticos, quizá en forma empírica porque no contamos en un principio con cultivos y con la identificación del germen, pero siempre se debe dar el manejo tomando en cuenta las características epidemiológicas regionales o locales del sitio donde se esté y siempre tomamos cultivos en forma temprana para identificar la bacteria y rectificar o ratificar el tratamiento.

El personal de salud debe usar el equipo de protección porque esto preserva a los miembros del personal y evita un deterioro como ha sucedido en algunos lugares, este equipo incluye gorro, gafas protectoras, botas antifluido, guantes y cubrebocas de alta seguridad.

Gracias a una microfotografía electrónica, hemos podido observar coronavirus pegados a las células del miocardio. Se ha descrito en la literatura que estos pacientes pueden hacer miocarditis, endocarditis, falla cardiaca o pueden ser alteraciones del ritmo importante, inclusive algunos pacientes han llegado infartados o desarrollan el infarto de miocardio. Con la observación de frotis de sangre periférica de un paciente con COVID se ha encontrado un síndrome de hematofagocitosis.

Esta enfermedad, desafortunadamente aparte de ser muy contagiosa y muy agresiva, es una enfermedad que deja secuelas letales y seguramente en los próximos meses o años vamos a tener en la consulta de Neumología y de Cardiología pacientes con secuelas porque deja fibrosis respiratoria, hipertensión pulmonar y puede dejar daño cardiovascular. Por esto, en China ya hay publicaciones en donde ya se han contemplado dos casos con trasplante pulmonar.

\section{EL MANEJO OBSTÉTRICO}

Particularmente, en el manejo obstétrico hay que hacer énfasis en la atención para reducir el riesgo de transmisión vertical que hasta el día de hoy no se ha demostrado auténticamente. Se recomienda pinzar inmediatamente el cordón umbilical ya sea que nazca a través de la vía vaginal o bien, que por las condiciones obstétricas, se haya decidido la vía abdominal. El aislamiento del recién nacido durante 14 días para no exponerlo a un contagio temprano y evaluar siempre el riesgo-beneficio en cada caso en particular.

En relación con la lactancia, existe la opción de los bancos de leche. Se propicia la lactancia porque está demostrada ahora con esta enfermedad viral la protección que infiere en forma natural la mamá a su hijo/bebé a través de la leche materna, la cual tiene inmunoglobulinas y factores protectores, entre ellos el factor de transferencia, que induce o favorece una protección celular. Entonces el contacto estrecho entre la madre y el hijo y el riesgo de transmitir los fluidos se debe de perder puesto que no se ha demostrado. No está contraindicada, al contrario, se debe propiciar la lactancia materna. Una vez que estamos seguros de que la mamá está fuera del periodo de contagio ya puede estar estrechamente con su bebé.

EI SARS-CoV-2 o COVID-19, como lo ha denominado la OMS, es multisistémico y los factores que interfieren para que un paciente que está en contacto con el virus pueda o no desarrollar la enfermedad son, primeramente que puede estar en contacto con un virus nativo que vino desde Asia o este virus ya ha mutado y puede perder infectividad o al contrario puede tornarse más agresivo. Entonces lo ideal es hacer una identificación a través del PCR-RT de que este individuo tiene el virus, pero idealmente debería poderse cuantificar. Estamos buscando ya en la actualidad en los hospitales nacionales la posibilidad de cuantificar para ver qué tantas réplicas hay del virus, que tanta carga viral tiene.

Otro aspecto importante es la respuesta inmunológica porque es individual y en el hospital general se ha explorado y hay diferencia en la respuesta inmunológica en los diferentes tipos de sujetos, ya sea la respuesta sérica o la respuesta celular. También qué impacto tiene esta respuesta inflamatoria y qué tanto podemos modularla. Por ejemplo, con la dexametasona utilizada tempranamente o, en un momento dado, la metilprednisolona. Qué tanta influencia tiene para disminuir la cascada de interleucinas o de quimiocinas en estos casos, y por supuesto factores como la edad, que va directamente proporcional al deterioro inmunológico. Por ello, los niños tienen una respuesta fantástica comparativamente con los casos de la tercera 
edad y el hecho de tener morbilidad, como es la obesidad como causa número uno, hipertensión arterial o diabetes.

Todo esto, según diversas publicaciones, son factores de susceptibilidad para el desarrollo de morbilidad o inclusive de muerte, el 20 de julio se publicó que había 81 defunciones maternas por COVID ya confirmadas si pudiéramos revisar la información reciente, veríamos que ya hay algunas mujeres que han fallecido y esto ha hecho que esta pandemia por este coronavirus se convierta en la causa número uno de muerte materna en nuestro país, así como en el 2009 constituyó los casos de influenza asociado al embarazo ahora tenemos casos de COVID-19; 40\% de estas mujeres fallecieron en el tercer trimestre de la gestación y el resto ocurrieron en el puerperio inmediato.

La razón de muerte, que es el número de muertes dividido entre los nacidos vivos, es de 6.8 por cada 100,000 nacimientos que es una tasa de morbilidad muy considerable. EI COVID-19 es la causa número uno; sin embargo, la muerte es causada por enfermedades respiratorias que complican el embarazo, porque no solamente es por COVID, también hay neumonías bacterianas y a veces neumonías mixtas o por casos que tienen probable COVID.

Vale la pena recordar que si bien, de acuerdo con la estadística del año pasado, en nuestro país fallecieron 29 mil sujetos a lo largo de todo el año por neumonía de causas múltiples, de orígenes múltiples, ahora tenemos las mismas neumonías bacterianas que en el invierno precisamente cobran el mayor número de vidas, pero ahora tenemos un virus asociado que nos está causando grandes problemas.

\section{MEDICINA CRÍTICA EN OBSTETRICIA}

El Hospital General de México, como muchos otros hospitales hace asistencia que es la principal función, hace docencia que es clásicamente el hospital/escuela de la Ciudad de México pero también la investigación junto con instituciones del sector como el Instituto Mexicano del Seguro Social y con diversos investigadores para buscar alternativas.

Algunos resultados iniciales que hay con respecto a lo que hemos encontrado en mujeres embarazadas son que las pacientes graves que llegan a medicina crítica en obstetricia y están en una terapia requieren todo el apoyo porque hacen falla orgánica múltiple, en este q-SOFA de los parámetros más importantes es la presión arterial sistólica, la frecuencia respiratoria y por supuesto el estado neurológico.

Se han medido algunas variables como los CD, la IgG y moléculas de respuesta inflamatoria como ferritina, PCR, dímero D, LDH, procalcitonina para demostrar que los pacientes se pueden infectar con bacterias, mioglobina, para demostrar que hacen rabdomiólisis y explica por qué estas pacientes tienen falla renal aguda y los linfocitos y neutrófilos como prototipos de la biometría hemática.

Comparativamente, los individuos de terapia, 29 que comparamos contra 24 asintomáticos y contra 47 pacientes que están hospitalizados, muestran diferencias muy importantes en su respuesta inmunológica. La IgG de asintomáticos es de 11 contra 5.1 de los que están hospitalizados y de 4.1 del paciente grave en terapia, los valores de la CD8, CD3 y CD4 presentan diferencias entre un grupo de casos y otros. En el grupo de terapia, estas moléculas de respuesta inflamatoria se encuentran disparadas, son casos graves que desarrollan falla orgánica múltiple porque aparte de que su respuesta inmunológica es pobre, tienen una respuesta inflamatoria severa y esto impacta a nivel multiorgánico.

Estudiamos otros grupos de casos, 24 asintomáticos y 24 que son negativos asintomáticos, la respuesta inmunológica entre un caso que ha dado positiva la PCR y uno que da un negativo es importante, finalmente el último grupo de ocho mujeres embarazadas que se han tratado con el doctor para demostrar que la respuesta inmunológica de las pacientes también está comprometida, no es una respuesta del todo favorable y esto las pone en malas condiciones.

Cuando se habla de que el embarazo es un estado, desde el punto de vista inmunológico privilegiado, pensaríamos que los cambios son muy dramáticos y que tienen una respuesta diferente y aquí lo estamos comprobando.

\section{MEDIDAS PREVENTIVAS}

¿Cuáles son las medidas preventivas importantes que debemos recordar? 
El lavado de manos con agua y jabón lo más frecuente posible, cuando esto no es posible tener a la mano o cargar una botella con gel antibacterial que contenga por lo menos $60 \%$ de alcohol y usarlo continuamente, quedarse en casa en todos los casos de gripe o catarro porque no sabemos si realmente puede ser un COVID, un catarro común o incluso casos de influenza, no saludar de mano ni de beso, cubrirse al estornudar con el antebrazo porque está demostrado que se magnifica la expulsión de virus cuando esto sucede, desinfectar toda la superficie de contacto con soluciones de cloro diluido, evitar viajar a lugares con reportes de epidemias, mantener las medidas en lo posible, no utilizar si es posible el transporte público por la posibilidad del contacto masivo, no asistir a eventos donde no se puede mantener una mínima distancia de por lo menos un metro/metro y medio entre una persona y otra.

Todas estas medidas que parecen muy sencillas epidemiológicamente han demostrado la diferencia entre una comunidad que puede llenarse de contagios, inclusive contagios graves.

\section{RECOMENDACIONES DE LA CDC EN LA PRÁCTICA CLÍNICA EN EL CONSULTORIO}

En el consultorio, específicamente de gineco y de obstetricia, las consultas deben ser programadas y también considerar que puede haber urgencias, recordar que la paciente obstétrica es una bomba de tiempo y que en cualquier momento puede requerir la vigilancia directa de su médico tratante, puede ser en la noche, un fin de semana, en época vacacional. Entonces, el médico que se compromete con su paciente tiene que estar disponible para poderla auxiliar.

Estratificar a las casos que tienen mayor riesgo para tener resultados adversos, una paciente con un índice de masa corporal arriba de 40 o que ha desarrollado diabetes gestacional, cardiópatas o que tiene una enfermedad de inmunocompromiso como el lupus (que no es tan raro en nuestro país) o por supuesto la paciente hipertensa que puede desarrollar preeclampsia tenemos que tenerlo en mente.

Promover permanentemente medidas preventivas como son todas las que acabamos de mencionar y tener a nuestro paciente monitoreado a través de la vía electrónica o telefónica para saber sus condiciones, establecer políticas de atención con el personal que está a nuestro alrededor para entender que todas estas medidas son importantes que las mantengamos vigentes, el uso desinfectante de manos a base de alcohol, jabón líquido, toallas desechables de papel para tirar en los basureros que tenemos que estar cambiando constantemente y respetar el espacio entre una y otra persona a dos metros o más de distancia.

No juntar a las pacientes en el consultorio, manejar la agenda de consulta programada y todo esto va a redundar en dar un mejor apoyo y evitar contagios masivos. Específicamente en el consultorio, la historia clínica está orientada a identificar factores de riesgo para saber que una paciente puede tener un riesgo mayor que otra y darle prioridad de atención y de comorbilidades, ese es el objetivo principal del control prenatal y cuando hablamos de control prenatal con enfoque de riesgo lo hacemos priorizando desde las primeras semanas de embarazo y haciendo un examen minucioso tanto materno como fetal.

El uso obligado de cubrebocas de los sujetos y por supuesto del personal médico, paramédico y del consultorio, limitar las visitas a un solo acompañante desde el consultorio y por supuesto limpiar las superficies con desinfectantes a base de cloro o de alcohol.

El uso del cubrebocas es histórico, ya se empezaban a utilizar en la pandemia de la gripe española, que ahora se sabe eran virus de la influenza y en aquella época se le bautizó como gripe española. Las medidas de quedarse en casa son para tratar de aplanar la curva, en la medida que menos personas anden en la calle innecesariamente propiciaremos menos contagios masivos y saturar los hospitales.

Particularmente, en el Hospital General de México con la doctora Guadalupe Guerrero que es la directora general, ha estado muy atenta a que todo el personal de salud mantenga medidas como: evitar saludar de beso, mano y sobre todo abrazos, no compartir alimentos ni bebidas, mantener limpia el área de trabajo, no usar corbata porque es un fómite y favorece la diseminación de microorganismos, evitar ingresar al comedor con uniforme 
de trabajo y lavarse las manos frecuentemente son medidas que se han difundido desde principios de la pandemia.

En la literatura ha habido predicciones Gaussianas de cómo estaría la pandemia, se han quedado un poco cortas porque se pensaba que parajunio la curva iba a estar prácticamente aplanada y hemos visto que no, esto es multifactorial, se debe a todo lo que hemos dicho al comportamiento poblacional, al tipo de virus, a la carga viral, a la respuesta inmunológica, a la respuesta inflamatoria y el contar con el apoyo en los hospitales para atender a nuestros pacientes.

En la enfermedad hay una fase de contagio, una fase donde inician los síntomas, una fase de hospitalización cuando esto es requerido, cuando ingresan los casos en Terapia Intensiva o inclusive la defunción. El periodo contagioso coincide con la detección de la PCR, con la detección de la lgM, de la IgG y el periodo de ventana, el estadio temprano, la fase activa y la fase final o cuando ya el sujeto está en una fase de recuperación y ya ha pasado la infección.

\section{AGRADECIMIENTOS}

Agradecimiento a los alumnos pasantes de servicio social MPSS Carmen Gabriela Jerónimo y QFB José
Eduardo Moreno Sanjuan de las licenciaturas de Medicina y Química Farmacéutica Biológica por su colaboración en la transcripción del texto.

\section{LECTURAS RECOMENDADAS}

1. Kuri MPA, Guzmán ME, De La Paz NE. Enfermedades emergentesy reemergentes. Gac Med Mex. 2015; 151:674-680.

2. Charles NC, Garza RML, Ramos JJ, Rivas EAM. Diagnóstico molecular del SARS-Coronavirus. Rev Mex Patol Clin. 2006; 53 (3): 146-150.

3. Cabrera GDA, Vargas VA, Grajales MC. Infección del nuevo coronavirus: nuevos legados. Rev Med Inst Mex Seguro Soc. 2014; 52 (4): 438-441.

4. Malik A, Medhat EMK, Ravi M, Sayed F. Middle East respiratory syndrome coronavirus during Pregnancy, Abu Dhabi, United Arab Emirates. 2013. Emerg Infect Dis. 2016; 22 (3): 515-517.

5. Young JS, Sung IS, Hee SJ, Yoon AS, Suk KE, Sil ChY et al. MERS-Cov infection in a pregnant woman in Korea. J Korean Med Sil. 2017; 32 (10): 1717-1720.

6. Alserehi H, Wali C, Alshukairi, Alraddadi B. Impact of Middle East respiratory syndrome coronavirus (MERS-CoV) on pregnancy and perinatal outcome. BMC Infect Dis. 2016; 16: 105

7. Kably AA, Olavarría GM, Sánchez AA, Roque SA, De Mendieta M, López MM. COVID-19 y sus repercusiones en la práctica ginecoobstétrica. Ginecol Obstet Mex. 2020; 88: 1-12. Disponible en: https://doi.org/10.24245/gom.v88id.4129.

\section{www. medig raphic.org.mx}




\section{Anexo 1: Recomendaciones para el consultorio.}

¿Qué medidas tomar ante la sospecha de COVID-19 en la paciente embarazada que acude al consultorio?

Si usted se encuentra en un consultorio donde recibe sujetos de diferentes edades y ha tenido embarazadas a las que les ha seguido el protocolo de atención del embarazo, las medidas que debería tomar como médico general en el consultorio cuando se encuentra una persona que no sabe si está enferma de COVID pero que en el transcurso de la entrevista y la exploración clínica se da cuenta que tiene algunos datos que pudieran hacerte sospechar que es positiva a COVID-19, son las siguientes: Una vez que nosotros recibimos una paciente, hay que seguir el protocolo de atención prenatal, es decir, el interrogatorio, la exploración, los exámenes básicos de laboratorio, los exámenes para ver las condiciones de viabilidad y bienestar del feto, que es básicamente un ultrasonido, y ante la sospecha de un caso sintomático o bien un asintomático. El sintomático es aquel paciente que puede tener fiebre, tos, malestar general, cefalea, mialgias, artralgias o bien tener cambios en la pérdida del olfato o de gusto que son relativamente comunes.

Este caso puede tener historia de estar o no en contacto con algún conocido o bien el otro escenario un paciente que está asintomático pero que nos refiere que estuvo en relación con un familiar, un amigo, un vecino y que se enteró que está positivo, aquí estamos obligados ante la sospecha a mandar a hacer una prueba de PCR para confirmar si la persona es positiva, si estuvo en contacto con el virus tenemos que aislarlo en principio de su familia para que no contagie a otros y hacer una vigilancia estrecha de su condición y hacer un seguimiento puntual a través del Servicio de Ginecoobstetricia, si por el contrario es negativa continúa su vigilancia a través del control pendiente. 